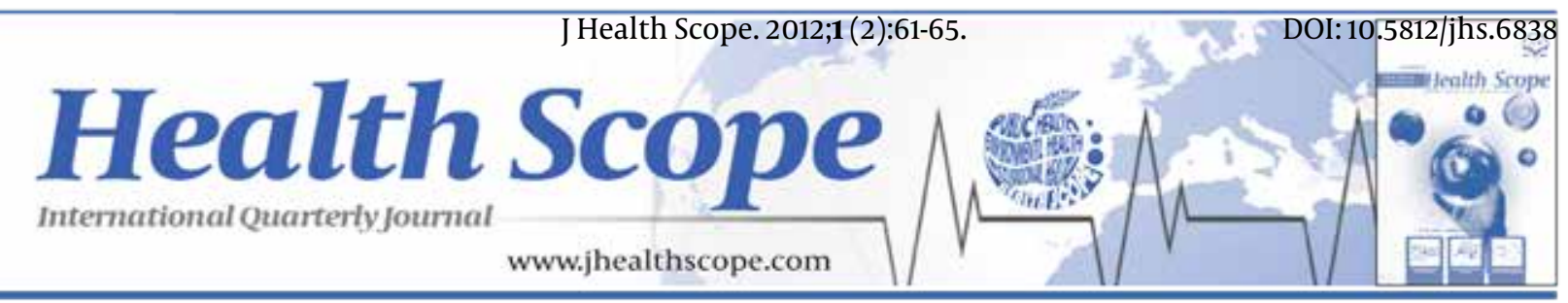

\title{
Human and Vehicle Factors in Motor Vehicle Crashes and Severity of Related Injuries in South East Iran
}

\author{
Mahdi Mohammadi ${ }^{1}$, Mahmoud Imani ${ }^{2}$, Fatemeh Tajari ${ }^{2}$, Farzad Akbari ${ }^{2}$, Fariborz Rashe- \\ $\mathrm{di}^{2}$, Ardavan Ghasemi ${ }^{2}$, Alireza Ansari-Moghaddam ${ }^{*}$ \\ ${ }^{1}$ Health Promotion Research Center, Zahedan University of Medical Sciences, Zahedan, IR Iran \\ ${ }^{2}$ Zahedan University of Medical Sciences, Zahedan, IR Iran
}

\begin{tabular}{l}
\hline A R T I C L E I N F O \\
\hline Article type: \\
Original Article \\
\hline Article history: \\
Received: 17 Jun 2012 \\
Revised: 20 Jun 2012 \\
Accepted: 24 Jun 2012 \\
\hline
\end{tabular}

Keywords:

Motor Vehicle

Iran

Injuries

\begin{abstract}
A B S T R A C T
Background: Motor vehicle crashes (MVC) are considered to be the most common safety challenge, causing more than a million deaths worldwide annually.

objectives: The current study was aimed at identifying the etiological role of human and vehicle safety factors in road crashes, and their effects on the severity of injury and fatality in the Sistan and Baluchistan Province, South East Iran.

Patients and Methods: In this study, 2703 MVC recorded at the police office during one year period, were reviewed. The profile of the crashes was comprised of data that included; demographic characteristics of the injured persons in a MCV, type of crash, type of vehicles involved, location of crash, as well as human, environmental and mechanical factors which contributed to the crash. Data were analysed using binary and multinomial logistic regressions.

Results: After adjusting for confounding factors, vehicles with passengers were $33 \%$ more likely to have a crash. Furthermore, pickup trucks and heavy trucks increased the chance of causing a crash, 1.66 and 1.84 times more than saloon cars, respectively. Vehicles made after 2005 had twice the risk of causing a crash than those made in 1980 or before. In addition, in a multivariate model; driver's age, type of vehicle and circumstances of car damage were contributing factors to the severity of injury.

Conclusions: Type and age of the car, the presence of passengers and the degree of damage to the car were the determinant factors for car crashes, and consequent severity of injury in the study area. Educational programs must be directed at promoting public knowledge about the consequences of their behavior as either a passenger or driver.
\end{abstract}

- Implication for health policy/practice/research/medical education:

The results of this study are important to the police officers, stakeholders and health policy makers for designing effective programs towards preventing and reducing the burden of motor vehicle crashes.

Please cite this paper as:

Mohammadi M, Imani M, Tajari F, Akbari F, Rashedi F, Ghjasemi A, Ansari-Moghadam A. Human and Vehicle Factors in Motor Vehicle Crashes and Severity of Related Injuries in South East Iran.J Health Scope. 2012;1 (2): 61-5.

* Corresponding author: Alireza Ansari-Moghaddam, Health Promotion Research Center, Zahedan University of Medical Sciences, Zahedan, IR Iran. Tel: +989155412155, Fax:+98-5412419403, E-mail: ansarialireza@yahoo.com 


\section{Background}

Motor vehicle crashes (MVC) are responsible for about 1.3 million deaths and hundreds of thousands of injuries and disabilities all around the world every year. Although road traffic injuries were the world's ninth most important health problem in 2004, it is predicted that they will be the fifth leading cause of death in 2030. Low-income and middle-income countries account for $90 \%$ of deaths in road accidents in the world, in spite of owning only half of the motor vehicles. Of these, poor and vulnerable groups have a disproportionate share of the burden arising from road traffic injuries (1). A study in Australia illustrated that after adjusting for confounding factors, vehicles made before 1984 had a 2.88 times greater chance of being involved in an injury compared to those made after 1994. Moreover, the crash risk increased for every year that the vehicles' age increased (2). Driving alone, when compared to driving with passengers, increases the risk of an accident (3-9). Furthermore, female drivers had a lower accident risk than males, while older (aged over 50) and younger drivers (18-21 years old) had an increased risk compared to middle-aged drivers (3). A population-based study in America showed that the strongest fatal crash initiation predictor was alcohol. Other risk factors for involvement in fatal crashes were; driving without a valid driving license, not wearing a seat belt, and experiencing a crash in the previous year (10). Less experience of driving, lack of traffic safety awareness, serious deficiencies in road infrastructure and limited funding, overloaded and oversized trucks, and using failed inspection vehicles in rural areas, have been identified as the major factors causing fatal accidents in China (11). In many South East Asian countries, the following factors are mainly responsible for the increasing number of road traffic injuries and deaths; a rapid increase in the number of motor vehicles, mixed traffic flows, inadequate infrastructural safety features, suboptimal levels of traffic safety law enforcement, and inadequate post-crash response (1). In Iran, a comprehensive road safety program was initiated in 2005 to enforce three interventions; seatbelt laws, motorcycle helmet laws and general traffic law enforcement, e. g. , use of speed cameras, patrols and mass media educational campaigns on national radio and television (12). Recently, similar to the majority of European countries, a points system of traffic laws was introduced in 2012. Accordingly, negative points have been defined for breaking each of the traffic laws. When the number of points exceeds a certain amount, the driving license is seized for a defined period of time. Furthermore, fines for traffic offences have increased significantly to prevent drivers from ignoring traffic laws. Although new strengthened traffic initiatives have helped to decrease figures related to crash outcomes in Iran, there are still barriers in road traffic injury prevention including; traffic safety culture, vehicle safety and infrastructure.

This study was carried out in the Sistan and Baluchistan Province, in the South East of Iran. This province is the largest in Iran with an area of $181785 \mathrm{~km}^{2}$ and a population of 2 .
4 million. It shares borders with Afghanistan and Pakistan. Hot-dry weather in the north and most parts of the west (Kavir-e-Loot Desert), and hot-humid weather in the south (Oman Sea) makes the area one of the driest regions in Iran. The only airway is from Zahedan in the north to Chabahar in the south of the province. Therefore, roads are used most frequently. Primary roads are two-way and narrow with insufficient road repairs, poor road lighting and contain many black spots. Secondary roads are also narrow and often sandy. This study focuses on the role of human and vehicle safety factors in causing road crashes and the relationship of those factors on the severity of injury and fatalities in this area.

\section{Patients and Methods}

The current study reviewed all recorded MVC at the police office from March 2009 to March 2010 in the Sistan and Baluchestan Province, in the southeast of Iran. Routinely, a nationally designed registration form is completed for each MVC by trained and experienced police officers at the crash scene. The form comprises data on; demographic characteristics of the injured persons in a MVC, type of crash, type of vehicle involved, location of the crash, as well as human, environmental and mechanical factors contributing to the crash. The definition of a MVC was taken to be any type of crash occurring on the road between two or more objects, where at least one of the objects involved was a moving vehicle. Reporting was done based on a registration form across all police offices in the province, to preclude any possibility of misclassification bias. Required information for the purposes of this study was extracted from the full police datasets by researchers with the assistance of police recordkeeper officers, under the supervision of the lead investigators. To ensure the confidentiality of the study subjects, no names or identifying information were extracted from the police data.

Less than 5\% missing value was observed for variables considered in this study. Data were entered in SPSS15 by two trained and experience operators and checked for any possible typing errors. The drivers involved in the accident, may be deemed to be at fault or determined to be innocent, and this was identified when a traffic crash was investigated by police officers. The information that was collected described the incidents using; numbers, frequencies, means and standard deviations. In addition, a logistic regression model was used to compare the characteristics of the driver at fault with drivers who were innocent for the purposes of this study. A multinomial logistic model was used to determine the risk factors of vehicle crash outcomes (noninjured, injured, death).

\section{Results}

In this study, 2703 vehicles were involved in road accidents. Among these drivers, 99. 4\% were male, $23.6 \%$ were under 25 years of age and $60 \%$ were between 25 and 45 years old, 9 . 
$1 \%$ were illiterate and $7.7 \%$ were university graduates. About $60 \%$ of the drivers caused the crash and $61.3 \%$ of these people were driving alone. Death occurred in 3.5\% of accidents, and $17.5 \%$ resulted in injury. Private cars and public services involved in the crashes were $77.5 \%$ and $18.1 \%$ respectively. A total of $49.3 \%$ of vehicles were saloon cars, $22.5 \%$ trucks, $15.1 \%$ heavy vehicles, 2 . $6 \%$ buses and $10.5 \%$ bikes. Following an accident, $61.7 \%$ of the vehicles were not able to move. Approximately $35.1 \%$ of these cars were manufactured in the last 5 years, and the age of $70.8 \%$ of the cars was no more than 10 years. In $62 \%$ of the accidents, cars collided in the front and in $15 \%$ the entire vehicle body was damaged. After adjusting for confounding factors (drivers' demographic factors and vehicle specifications) through a binary logistic model, vehicles with passengers had 1.33 times more chance of being the cause of a crash. Furthermore, pickup trucks and heavy trucks increased the chances of causing a crash 1.66 and 1. 84 times more than saloon cars, respectively. Vehicles made

\begin{tabular}{|c|c|c|c|c|}
\hline & \multicolumn{2}{|c|}{ Unadjusted } & \multicolumn{2}{|c|}{ Adjusted } \\
\hline & OR & 95\% CI & OR & 95\% CI \\
\hline \multicolumn{5}{|l|}{ Passenger } \\
\hline No & 1.00 & & 1.00 & \\
\hline Yes & 1.31 & $(1.12,1.53)$ & 1.33 & $(1.11,1.60)$ \\
\hline \multicolumn{5}{|l|}{ Type of vehicle } \\
\hline Saloon car & 1.00 & & 1. 00 & \\
\hline Minibus, autobus & 0.86 & $(0.56,1.33)$ & 0.60 & $(0.35,1.03)$ \\
\hline Pickup truck & 0.50 & $(0.27,0.91)$ & 1. 66 & $(1.28,2.16)$ \\
\hline Truck & 1.27 & $(0.81,2.00)$ & 1. 84 & $(1.35,2.50)$ \\
\hline Bike & 1.31 & $(0.81,2.11)$ & 0.71 & $(0.52,0.96)$ \\
\hline Trailer & 0.51 & $(0.32,0.82)$ & 1.19 & $(0.73,1.96)$ \\
\hline \multicolumn{5}{|l|}{ Make } \\
\hline$\leq 1980$ & 1.00 & & 1.00 & \\
\hline$(1980,1990]$ & 1.39 & $(0.76,2.55)$ & 1.78 & $(0.92,3.42)$ \\
\hline$(1990,2000]$ & 1.07 & $(0.60,1.93)$ & 1.65 & $(0.88,3.09)$ \\
\hline$(2000,2005]$ & 0.99 & $(0.57,1.76)$ & 1.59 & $(0.87,2.93)$ \\
\hline$>2005$ & 1.24 & $(0.70,2.19)$ & 2.07 & $(1.12,3.82)$ \\
\hline
\end{tabular}

\begin{tabular}{|c|c|c|c|c|}
\hline & \multicolumn{2}{|c|}{ Injury } & \multicolumn{2}{|c|}{ Death } \\
\hline & Unadjusted OR (95\% CI) & Adjusted OR (95\% CI) & Unadjusted OR (95\% CI) & Adjusted OR (95\% CI) \\
\hline \multicolumn{5}{|l|}{ Driver's age } \\
\hline$\leq 25$ & $2.20(1.53,3.16)$ & $1.40(0.93,2.13)$ & 3. $60(1.49,8.73)$ & $2.80(1.03,7.64)$ \\
\hline $25-35$ & $1.52(1.06,2.16)$ & $1.19(0.80,1.77)$ & 2. $67(1.12,6.37)$ & $2.21(0.84,5.85)$ \\
\hline $35-45$ & $1.57(1.08,2.29)$ & $1.25(0.82,1.91)$ & $1.87(0.73,4.80)$ & $1.87(0.67,5.21)$ \\
\hline$>45$ & 1.00 & 1. 00 & 1.00 & 1. 00 \\
\hline \multicolumn{5}{|l|}{ Type of vehicle } \\
\hline Saloon car & $4.30(1.56,11.87)$ & $3.60(1.10,11.74)$ & $1.57(0.37,6.60)$ & $0.65(0.15,2.89)$ \\
\hline Mini, autobus & $2.35(0.66,8.42)$ & $1.81(0.38,8.61)$ & $2.69(0.48,15.19)$ & $2.48(0.42,14.79)$ \\
\hline Pickup truck & $6.41(2.30,17.82)$ & $4.98(1.51,16.44)$ & $2.69(0.63,11.52)$ & $1.34(0.30,6.06)$ \\
\hline Truck & $0.86(0.27,2.72)$ & $0.99(0.27,3.65)$ & $0.40(0.07,2.42)$ & $0.33(0.05,2.06)$ \\
\hline Bike & $7.11(2.51,20.14)$ & $6.98(2.07,23.58)$ & $2.44(0.53,11.14)$ & $1.32(0.26,6.65)$ \\
\hline Trailer & 1. 00 & 1. 00 & 1. 00 & 1. 00 \\
\hline \multicolumn{5}{|l|}{ Car damage } \\
\hline Front Whole & 1.00 & 1.00 & 1.00 & 1.00 \\
\hline Body & $3.60(2.76,4.69)$ & $3.72(2.82,4.91)$ & $4.91(3.07,7.83)$ & $5.42(3.30,8.91)$ \\
\hline Rear & $0.42(0.27,0.67)$ & $0.53(0.33,0.87)$ & $0.31(0.09,0.99)$ & $0.82(0.67,1.15)$ \\
\hline Right & $0.87(0.48,1.59)$ & $0.88(0.47,1.67)$ & $0.34(0.05,2.49)$ & $0.38(0.05,2.85)$ \\
\hline Left & $0.64(0.38,1.06)$ & $0.68(0.40,1.15)$ & $0.36(0.09,1.50)$ & $0.40(0.09,1.67)$ \\
\hline
\end{tabular}

${ }^{a}$ Reference category was taken from crashes with non-injured outcomes 
after 2005 had a 2.1 times greater risk of causing a crash than those made in 1980 or earlier. However, drivers' sex $(P$ $=0.204)$ and education $(P=0.138)$ were not significantly related to the cause of a crash (Table 1).

After adjusting for confounders (drivers' demographic factors and vehicle specifications) through a multinomial logistic model, young drivers aged 25 years or less increased the risk of a fatal crash 2.8 times more than those aged over 45 years old. Type of vehicle also contributed significantly to the severity of the injury. The risk of injury in saloon cars, pickup trucks and bikes increased 3. 6, 4.98 and 6.98 times more than trailers, respectively. Compared to a front collision, whole body damage of a vehicle increased the risk of injury by 3.72 times and the risk of fatalities by 5.42 times (Table 2).

\section{Conclusion}

This study aimed to investigate the driver and vehicle factors involved in causing a crash and also the outcomes of a crash. Cars with passengers, trucks and pickup trucks and also cars made after 2005, made a significant contribution in causing a crash. Furthermore, young drivers (under 45 years old) were more often responsible for a fatal crash. Although the type of vehicle increased the risk of injuries, it was not a significant risk factor for fatalities. Whole body damage of a car increased the risk of injury, as well as fatalities. The current study showed that driving with passengers increased the risk of causing a car crash, whereas a protective effect for the presence of passengers has been reported in other studies. The presence of passengers was more protective in drivers over 45 years old, than for younger drivers. Young male passengers increased a younger drivers' crash potential, whereas female passengers who accompanied male drivers strongly decreased the risk of a crash. For drivers aged 65 to 70 , although the presence of passengers reduced the risk of some unsafe actions (eg, driving the wrong way), it increased the risk of other actions such as; ignoring signs, warnings, and right of way (3-9). Trucks were identified to be responsible for causing some of the accidents. Pickup trucks are usually used in rural areas by farmers. They typically use this type of vehicle to take their products to the urban areas for sale. Therefore, most pickup drivers do not have enough knowledge of traffic laws and do not always comply with traffic laws. Up to a few years ago, the driving test was not taken very seriously and drivers with limited ability were able to receive their driving license. New standards have been introduced recently which requires people to take some compulsory courses before taking their driving test. This may make people more familiar with the traffic laws, but the driving test itself needs to be taken more seriously by the examiners.

Cars made after 2005 caused more crashes. This contradicts the results of a study in Australia (2). However, a significant relationship between the vehicles' performance and drivers' risk-taking behavior has also been re- ported. High vehicle performance and a greater number of safety features may result in higher risk behavior (13). Most new cars can attain high road speeds, which are not consistent with current road infrastructures in Iran. The lack of separate lanes for low speed vehicles, insufficient road repairs, large number of accident black spots, inadequately separated roads, non-standard roads, lack of guard rails on dangerous roads, inadequate traffic signs and insufficient road lighting, are the main problems with road infrastructure which have been identified. Furthermore, some of the new cars made in Iran also have insufficient safety features such as; vehicle air bags, ABS brakes and compatibility of the vehicles with the roads $(14,15)$. Human factors are also involved in causing accidents in Iran. There is always a great sense of urgency in road-users, many of whom are less cautious and have received insufficient driver training prior to receiving their license. This is highlighted particularly in younger drivers who are responsible for many fatal crashes. On the other hand; lack of authority for traffic police, insufficient modern equipment for traffic police monitoring, difficulty in confiscating vehicles from offenders, the public's lack of confidence in the police and inability to sustain a prevention plan, are the major barriers to road traffic injury prevention in Iran $(14,15)$.

\section{Acknowledgements}

The authors would like to thank police authorities for granting permission to obtain relevant data for this study from their registered files. They also wish to thank the police officers who were responsible for investigating traffic crashes, and completing related forms at the site of the accidents, as well as the police record-keeping officers.

\section{Authors' Contribution}

The overall implementation of this study including data extraction and analysis, report writing and manuscript preparation were the results of joint efforts by multiple individuals who are listed as co-authors of this paper.

\section{Financial Disclosure}

None declared.

\section{Funding/Support}

This research was not supported financially. However, permission was given to the authors by traffic police to use their recorded data.

\section{References}

1. Organization WH. Global status report on road safety 2009 Genova, Switzerland: World Health Organization. 2012; Available from: www. who. int/violence_injury_prevention/road_safety_ status/2009/en/index. html.

2. Blows S, Ivers RQ, Woodward M, Connor J, Ameratunga S, Norton R. Vehicle year and the risk of car crash injury. Inj Prev. 2003;9 
(4):353-6.

3. Vollrath M, Meilinger T, Kruger HP. How the presence of passengers influences the risk of a collision with another vehicle. Accident Anal Prev. 2002;34:649-54.

4. Bedard M, Meyers JR. The influence of passengers on older drivers involved in fatal crashes. Exp Aging Res. 2004;30 (2):205-15.

5. Bunn TL, Yu L, Slavova S, Bathke A. The effects of semi truck driver age and gender and the presence of passengers on collisions with other vehicles. Traffic Inj Prev. 2009;10 (3):266-72.

6. Lee C, Abdel-Aty M. Presence of passengers: Does it increase or reduce driver's crash potential? Accident Anal Prev. 2008;40:1703-12.

7. Williams AF, Ferguson SA, McCartt AT. Passenger effects on teenage driving and opportunities for reducing the risks of such travel. J Safety Res. 2007;38 (4):381-90.

8. Rueda-Domingo T, Lardelli-Claret P, Luna-del-Castillo J, JimenezMoleon JJ, Bueno-Cavanillas A. The influence of passengers on the risk of the driver causing a car collision in Spain: Analysis of collisions from 1990 to 1999. Accident Anal Prev. 2004;36 (3):481-9.

9. Vollrath M, Meilinger T, Kruger HP. How the presence of passen- gers influences the risk of a collision with another vehicle. Accident Anal Prev. 2002;34 (5):649-54.

10. Perneger T, Smith GS. The driver's role in fatal two-car crashes: a paired "case-control" study. Am J Epidemiol. 1991;134 (10):1138-45.

11. Zhao Sa. Rapid motorization and road traffic accidents in China. Dalian University of Technology, Dalian, Chin. Presented at 11th World Conference on Transport Research ; Berkeley, CA; 2007.

12. Naeem Z. Road Traffic Injuries-Changing Trend? Int J Health Sci. 2010;4 (2):v-viii.

13. Horswill MS, Coster ME. The effect of vehicle characteristics on drivers' risk-taking behaviour. Ergonomic. 2002;45 (2):85-104.

14. Khorasani-Zavareh D, Mohammadi R, Khankeh HR, Laflamme L, Bikmoradi A, Haglund BJ. The requirements and challenges in preventing of road traffic injury in Iran. A qualitative study. BMC Public Health. 2009;9:486.

15. Khorasani-Zavareh D, Khankeh HR, Mohammadi R, Laflamme L, Bikmoradi A, Haglund BJ. Post-crash management of road traffic injury victims in Iran. Stakeholders' views on current barriers and potential facilitators. BMC Emerg Med. 2009;9:8. 